\title{
Capítulos de uma História: a decisão do STF sobre união homoafetiva à luz do direito como integridade
}

\section{Chapters of a Story: the STF ruling about same-sex unions in the light of law as integrity}

\author{
Antonio Moreira Maués \\ Universidade Federal do Pará, Belém - PA, Brasil
}

\begin{abstract}
Resumo: Este trabalho analisa a decisão do STF que reconheceu a união homoafetiva, com base na teoria do direito como integridade de R. Dworkin e em pesquisa documental sobre o tema. Critica o uso da ideia de intenção do legislador como fundamento para afirmar que a Constituição proíbe as uniões homoafetivas e argumenta que, no direito brasileiro, a construção do direito à igualdade no campo da orientação sexual autoriza o reconhecimento dessas uniões pelo poder judiciário.
\end{abstract}

Palavras-chave: Uniões Homoafetivas. Direito à Igualdade. Intenção do Legislador.

\begin{abstract}
STF ruling that recognized same-sex unions, based on law as integrity theory of R. Dworkin and on documentary research about the subject. It criticizes the use of legislative intent as a ground to conclude that the Constitution prohibits same-sex unions and argues that the construction of the right to equality in the field of sexual orientation in Brazilian law authorizes the judiciary to recognize these unions.
\end{abstract}

Keywords: Same-sex Unions. Right to Equality. Legislative Intent.

\section{Introdução}

No julgamento da ADIn n. 4.277, em maio de 2011, página 5, o Supremo Tribunal Federal (STF) reconheceu juridicamente as uniões es-

Recebido em: 1\%/10/2014

Revisado em: 15/04/2015

Aprovado em: 19/05/2015 
táveis homoafetivas "com as mesmas regras e consequências da união estável heteroafetiva". A decisão do STF atraiu críticas da comunidade jurídica e resistências na própria esfera judicial ${ }^{2}$, ambas baseadas na ideia de que o STF extrapolou os limites de suas funções e modificou o conteúdo da Constituição.

Apesar desse ponto comum, é possível distinguir duas linhas de argumentos nas críticas à decisão do STF. A primeira delas considera que a Constituição proíbe o reconhecimento de uniões entre pessoas do mesmo sexo $^{3}$, enquanto a segunda afirma que, embora a Constituição não proíba o reconhecimento da união homoafetiva, o judiciário não tem competência para tomar essa decisão ${ }^{4}$. Para a primeira crítica, so-

\footnotetext{
1 ADIn n. 4.277, p. 5. A íntegra do acórdão do STF encontra-se disponível em: <http:// redir.stf.jus.br/paginadorpub/paginador.jsp?docTP $=\mathrm{AC} \&$ docID $=628635>$. As referências à decisão feitas neste trabalho utilizarão os números das páginas do arquivo em pdf. A ADIn n. 4.277 foi julgada conjuntamente com a ADPF n. 132.

2 Em Goiânia, o juiz titular da Vara da Fazenda Pública anulou de ofício um contrato de união estável que havia sido firmado após a decisão do STF e determinou que os cartórios se recusassem a registrar esse tipo de união. A decisão foi posteriormente cassada pela Corregedoria do Tribunal de Justiça de Goiás. Conferir em: < http://blogs. estadao.com.br/jt-cidades/uniao-homossexual-vai-voltar-ao-stf/> e <http:/g1.globo. com/politica/noticia/2011/06/tj-go-cassa-decisao-que-anulou-uniao-estavel-de-casalgay.html >. Acesso em: 24 abr. 2014. Apesar dessas resistências, o caráter vinculante da decisão do STF ensejou a edição, pelo Conselho Nacional de Justiça (CNJ), da Resolução n. 175/2013, segundo a qual: “Art. $1^{\circ}$ É vedada às autoridades competentes a recusa de habilitação, celebração de casamento civil ou de conversão de união estável em casamento entre pessoas de mesmo sexo". Contra essa Resolução, o Partido Social Cristão (PSC) impetrou junto ao STF o Mandado de Segurança n. 32.077, o qual foi extinto sem julgamento de mérito pelo Min. Luiz Fux, que considerou essa via inadequada para questionar o ato normativo do CNJ e observou, ainda, que a Resolução do CNJ atendeu aos objetivos da Constituição, estando de acordo com o julgamento da ADIn n. 4.277.

3 Conferir em Venosa (2008, p. 42), para quem a Constituição afasta "[...] qualquer ideia que permita considerar a união de pessoas do mesmo sexo como união estável nos termos da lei. O relacionamento homossexual [...] por mais estável e duradouro que seja, não receberá a proteção constitucional e, consequentemente, não se amolda aos direitos de índole familiar criados pelo legislador ordinário".

4 Conferir em Streck, Barretto e Oliveira (2009), para quem a regulamentação das uniões homoafetivas pelo STF não estaria baseada em uma interpretação possível do texto constitucional, mas nos "valores" defendidos pelos juízes.
} 
mente uma emenda constitucional poderia incorporar a união estável homoafetiva ao nosso ordenamento; para a segunda crítica, caberia à lei promover esse reconhecimento.

Neste trabalho, pretende-se enfrentar ambas as críticas, utilizando como referência a teoria do direito como integridade de R. Dworkin. A resposta à primeira crítica destaca que seu fundamento é a ideia de intenção do legislador e busca demonstrar que essa "intenção" não pode ser utilizada como critério de interpretação da Constituição. A resposta à segunda crítica destaca que a correta interpretação do direito à igualdade no caso autoriza o judiciário a decidir dessa maneira ${ }^{5}$. Para sustentar esses argumentos, serão utilizados dados resultantes de pesquisas nos Anais da Assembleia Nacional Constituinte e na legislação e jurisprudência sobre a matéria, visando interpretar a história que nos permite avaliar a decisão do STF.

\section{Intenções}

Não há dúvidas de que, ao se referir à união estável, o artigo 226, $\S 3^{\circ}$ da CR utiliza os termos "entre homem e mulher", porém, tampouco pairam dúvidas quanto ao fato de que a Constituição não contém nenhum dispositivo que proíba o reconhecimento das uniões entre pessoas do mesmo sexo. Apesar disso, afirma-se que o legislador constituinte, ao optar pela expressão "entre homem e mulher", pretendeu excluir as relações homossexuais do âmbito da união estável, o que significa dizer que a decisão do STF desrespeitou sua intenção.

No fundamento dessa crítica encontra-se um fato psicológico: ela nos conduz a buscar aquilo que habitava a "mente" dos constituintes quando votaram o artigo $226, \S 3^{\circ}$ da $\mathrm{CR}$, ou seja, quais teriam sido suas motivações para decidirem dessa maneira o tema da união estável. Uma vez que esse fato psicológico ocorreu no passado, sua "descoberta" depende de uma investigação histórica, cujas fontes são os Anais da As-

5 Outros argumentos de defesa da decisão do STF se encontram em Rios, Golin e Leiva (2011), Moreira (2012), Nigro (2012), Menezes e Oliveira (2012) e Bahia e Vecchiatti (2013). 
sembleia Nacional Constituinte e quaisquer outros documentos relevantes para a identificação da intenção do legislador constituinte.

Assim, a intenção do legislador é compreendida como a "ideia" que ele quis comunicar por meio da lei, tornando o ato de legislar semelhante a um ato de comunicação em que uma pessoa informa a outra, por meio de palavras, quais são suas intenções. O mais importante desafio a essa teoria foi lançado por R. Dworkin no decorrer de sua obra ${ }^{6}$, a qual será tomada como referência nos parágrafos seguintes para refletir sobre sua validade no caso da união homoafetiva.

Dworkin inicia sua análise destacando que há várias maneiras de compreender a intenção do legislador, o que impõe ao intérprete escolher uma determinada concepção para guiar sua busca. Essa escolha, por sua vez, condiciona as conclusões da investigação e torna mais polêmica a interpretação da Constituição baseada na intenção do legislador, pois diferentes concepções levam a respostas também diferentes no caso concreto. (DWORKIN, 2005, p. 52)

Mesmo quando se toma como objeto de análise um legislador individual, suas intenções podem ser entendidas de várias maneiras. Por exemplo, é possível considerar como intenção do legislador que a lei somente seja aplicada aos casos sobre os quais ele pensou ao formulá-la; ou, em sentido contrário, que sua intenção é que a lei seja aplicada também aos casos que ele não tinha em mente quando a formulou. Tratandose da aplicação de uma norma proibitiva, a primeira concepção indica que

6 A primeira crítica sistemática de Dworkin à ideia de intenção do legislador aparece em "Uma Questão de Princípio" (DWORKIN, 2005, cap. 2) e o tema é retomado em sua obra principal, "O Império do Direito" (DWORKIN, 1999, cap. 9). O conjunto dos textos fundamentais de Dworkin sobre a matéria se completa com o trabalho publicado em "Justiça de Toga" (DWORKIN, 2006, cap. 5). Para Goldsworthy (2000), houve mudanças importantes no desenvolvimento do pensamento de Dworkin sobre a questão, o que o teria aproximado, no último texto citado, de uma concepção "originalista", que valoriza a intenção do legislador na interpretação do direito. No entanto, Goldsworthy confunde com uma mudança de posição a ênfase que Dworkin dedica nesse trabalho à análise da interpretação textual da Constituição, a qual continua regida pelo cânone da interpretação construtiva e não diminui a importância da interpretação do conjunto da prática constitucional (DWORKIN, 2006, p. 117-118, 120 e 123). Para outras críticas à noção de legislação como ato de comunicação, conferir em Ekins (2012). 
nenhuma ação deve ser proibida a menos que o legislador tenha pretendido fazê-lo; já a segunda concepção indica que as palavras do legislador devem ser entendidas de modo a alcançar situações similares àquelas que ele imaginou. (DWORKIN, 2005, p. 53-54)

Quando se passa para a análise da intenção de um grupo de legisladores, Dworkin demonstra que há vários outros obstáculos na busca de determinar quais seriam os estados psicológicos relevantes para a análise.

Uma primeira dificuldade reside na definição dos indivíduos que devem ser levados em conta: todos os membros da constituinte ou somente aqueles que votaram a favor de determinada proposição? As intenções daqueles que se manifestaram durante os debates deve ter mais importância do que as intenções dos demais? As intenções dos cidadãos e cidadãs que participaram dos debates são relevantes? Devem ser considerados somente os eventos mentais presentes no momento em que a proposição é aprovada, ou também os estados psicológicos posteriores dos legisladores? (DWORKIN, 1999, p. 382-390; DWORKIN, 2005, p. 57-64)

Tais questões são muito importantes diante do contexto de elaboração da Constituição de 1988. Forjada em um processo que contou, desde sua primeira fase, com a participação de todos os membros da Assembleia, o número de votações ocorrido durante o processo foi bastante alto, embora, no momento final das votações em plenário, os acordos que formaram as maiorias fossem feitos entre as lideranças, com menor participação dos demais membros dos partidos (LOPES, 2008; MAUÉS; SANTOS, 2008; PILATTI, 2008). Por outro lado, a expressiva participação popular, efetivada por meio de sugestões, audiências públicas e emendas populares, influenciou muitas das disposições finalmente aprovadas na Constituinte. Cabe lembrar, ainda, que, após a promulgação da Constituição, os membros da Assembleia continuaram exercendo seus mandatos na Câmara dos Deputados e no Senado, sendo responsáveis pela regulamentação dos dispositivos constitucionais.

Caso o intérprete escolha restringir sua pesquisa aos legisladores que efetivamente votaram a favor da proposta, isso não significa que os problemas desaparecerão, uma vez que pode haver divergências entre as intenções dos integrantes da maioria (DWORKIN, 1999, p. 385-386; 
DWORKIN, 2005, p. 63-64), situação em que o intérprete se vê obrigado a estabelecer um critério para combinar essas várias opiniões diferentes e formar uma "intenção do grupo". Porém, vários critérios podem ser utilizados para produzir essa combinação. O intérprete pode escolher, por exemplo, basear-se na "intenção majoritária", utilizando as intenções daquele grupo que seria suficiente para aprovar a proposta, ou pode se basear na "intenção representativa", buscando uma "média" das opiniões que represente a maioria dos legisladores. Essas opções, no entanto, não conduzem necessariamente às mesmas conclusões.

Mesmo que o intérprete pudesse identificar uma opinião compartilhada por todos os constituintes que votaram a favor de uma proposta, isso não eliminaria a complexidade dos estados psicológicos que devem ser levados em consideração. Um exemplo dessa complexidade, indica Dworkin (1999, p. 386-390; 2005, p. 58-60), aparece quando há divergências entre as expectativas (expectations) e os desejos (hopes) do legislador. As expectativas são compostas pelo modo como o legislador prevê que as palavras da lei serão compreendidas; já os seus desejos são compostos pelo modo como ele gostaria que essas palavras fossem compreendidas. Embora seja comum que expectativas e desejos coincidam, o legislador pode se encontrar diante de uma situação em que ele prevê que a lei será aplicada de determinada maneira, embora preferisse que isso não viesse a ocorrer. Tal situação deriva do fato de que, no processo legislativo, o legislador individual não se coloca na mesma posição de uma pessoa que está conversando com outra e pode escolher as palavras que vai utilizar, esperando ser compreendido da maneira que deseja ser compreendido. Ao contrário, o legislador individual pode votar a favor de uma determinada proposição mesmo que ela não corresponda exatamente aos seus desejos. Nessa situação, a qual dos dois estados deve ser dada prioridade para definir a intenção do legislador?

Imagina-se a seguinte situação: alguns constituintes entendem que não deve haver discriminação em razão da orientação sexual. Eles não tiveram a oportunidade de apresentar uma emenda ao projeto de Constituição que incluísse expressamente como entidade familiar a união entre pessoas do mesmo sexo e, portanto, sua opção é votar a favor ou contra a redação do artigo $226, \S 3^{\circ}$. No momento dessa votação, os constituintes 
podem compartilhar a expectativa de que o dispositivo será interpretado de maneira restritiva, sem alcançar as uniões homossexuais, porém, eles podem compartilhar também o desejo de que ocorresse o contrário. Assim, esses constituintes não se encontram na mesma posição das pessoas que estão expressando suas ideias durante uma conversa, pois eles estão decidindo votar a favor de um texto cuja interpretação pode vir a ser contrária a seus desejos. Isso nos ajuda a concluir que a ausência de discussão sobre as relações homossexuais na Constituinte não é suficiente para comprovar que havia a "intenção" de exclui-las do âmbito da união estável.

Imagina-se agora um constituinte que, nas fases iniciais da Assembleia, tenha defendido uma emenda estabelecendo que a família se constitua exclusivamente por meio do casamento. Após a derrota dessa proposição, ele vota a favor do texto final do artigo $226, \S 3^{\circ}$, na medida em que o dispositivo prevê que a lei deve facilitar a conversão da união estável em casamento. Nesse caso, também pode haver um conflito entre expectativas e desejos: o constituinte pode desejar que a regulamentação da união estável não deva ser feita, mantendo, na prática, a exclusividade do casamento como forma de constituição da família, embora ele preveja que o legislador irá regulamentar o dispositivo constitucional.

Nesses exemplos de disjunção entre expectativas e desejos, qual deveria ser a opção do intérprete? Seria fácil cogitar que os desejos manifestam de modo mais autêntico a intenção do legislador (DWORKIN, 1999, p. 388), porém, como se viu no segundo exemplo, alguns desses desejos podem não ser considerados válidos pelo direito, uma vez que negam eficácia à Constituição. De modo similar, também não poderia ser admitida uma interpretação fundada no argumento de que o constituinte, embora não se opusesse à união homoafetiva, votasse contra uma eventual proposta de reconhecimento porque seu desejo é que a rejeição da proposta o ajude a ser reeleito por um eleitorado fortemente conservador em temas envolvendo a família. Isso significa que o intérprete deve se orientar pelas expectativas do legislador? Essa conclusão tampouco pode ser obtida quando se percebe que essas expectativas representam, na maioria dos casos, uma previsão sobre como a norma será interpretada pelos juízes, o que nos colocaria em uma situação demasiadamente hipotética: o fundamento da decisão judicial 
seria aquilo que o juiz imagina que o legislador teria imaginado sobre como ele decidiria um caso. (DWORKIN, 1999, p. 389)

Além da possível divergência entre as expectativas e os desejos dos legisladores, outra situação é ainda mais previsível: os constituintes, simplesmente, não pensaram na repercussão da criação do instituto da união estável sobre as relações homossexuais. Essa cogitação encontra apoio, inclusive, nos Anais da Assembleia Nacional Constituinte. Os primeiros debates sobre o tema da união estável ocorreram no âmbito da "Subcomissão da Família, do Menor e do Idoso", que integrava a "Comissão da Família, Educação, Cultura e Esportes, da Ciência e Tecnologia e da Comunicação". A leitura dos Anais dessa Subcomissão demonstra que o tema da "natureza da sociedade conjugal" foi escolhido como um dos eixos de discussão, tendo sido objeto da primeira audiência pública por ela realizada. Nas discussões que levaram à aprovação da primeira proposta de reconhecimento das uniões estáveis na Constituinte, destacam-se os argumentos favoráveis à legalização das então chamadas "uniões de fato" ou "uniões livres", de modo a oferecer a proteção do Estado a outras formas de família, muito presentes na sociedade brasileira, que não eram oriundas do casamento ${ }^{7}$. Em nenhum momento dos debates nessa Subcomissão e nas fases posteriores do processo constituinte a questão do reconhecimento das uniões homossexuais foi mencionada ${ }^{8}$.

\footnotetext{
7 Assembleia Nacional Constituinte, Subcomissão da Família, do Menor e do Idoso (Atas das Comissões, p. 22-36, 219-227, 249-250).

8 No âmbito da Subcomissão da Família, do Menor e do Idoso, há um único momento em que a palavra "gays" é citada, em meio à discussão sobre a proteção da família constituída por um dos pais e seus dependentes, pelo seu Presidente, Nelson Aguiar: "Dois gays resolvem viver em sociedade - eles querem que o Estado reconheça o direito à proteção familiar. Então, essa redação ficaria: para efeito de proteção do Estado é reconhecida a união estável entre o homem, a mulher e seus dependentes como entidade familiar". (Assembleia Nacional Constituinte, Subcomissão da Família, do Menor e do Idoso (Atas das Comissões, p. 249-250) Cabe observar que, nas fases posteriores da Constituinte, houve poucos debates sobre o tema da família no momento das votações. A Comissão da Família, Educação, Cultura e Esportes, da Ciência e Tecnologia e da Comunicação rejeitou os substitutivos apresentados pelo Relator e deixou de aprovar seu anteprojeto, enquanto na Comissão de Sistematização os trabalhos foram encerrados sem que houvessem sido votados os destaques sobre família. Já no Plenário, a emenda de fusão sobre o capítulo "Da Família, da Criança, do Adolescente e do Idoso" foi aprovado por ampla maioria
} 
Diante dessa falta de elementos empíricos, somente por meio de um argumento contrafactual seria possível identificar a intenção do legislador (DWORKIN, 1999, p. 390-393). Um exemplo de argumento contrafactual poderia partir da seguinte questão: se houvesse sido proposta uma emenda ao projeto de Constituição, estendendo o reconhecimento da união estável às relações entre pessoas do mesmo sexo, ela teria sido aprovada? Uma primeira tentativa de resposta a essa questão poderia buscar, em outras manifestações dos constituintes, evidências de sua opinião sobre a homossexualidade. Assim, caso a maioria dos constituintes partilhasse opiniões discriminatórias sobre os homossexuais, seria possível deduzir que eles teriam votado contra a emenda. No entanto, esse caminho nos levaria de volta às dificuldades que se enfrenta para eleger entre as expectativas e os desejos dos constituintes, acentuadas pelo caráter hipotético do raciocínio.

$\mathrm{O}$ argumento contrafactual torna-se ainda mais difícil de ser admitido quando se reconhece que a decisão de voto dos constituintes depende de uma série de fatores que somente podem ser apreciados em situações reais. Por exemplo, é comum nos processos constituintes marcados pelo pluralismo, tal como o brasileiro, que as maiorias sejam formadas por meio de acordos baseados em concessões mútuas (MAUÉS; SANTOS,

de 435 votos no $1^{\circ}$ turno e resultou de um acordo entre os partidos políticos (Diário da Assembleia Nacional Constituinte, n. 237, p. 684-687). Na votação dos destaques, as discussões limitaram-se aos temas do divórcio, do planejamento familiar, dos direitos dos idosos e da criação de um fundo de proteção à família carente (Diário da Assembleia Nacional Constituinte, n. 237, p. 690-704). Em seu voto na ADIn n. 4.277, o Min. Ricardo Lewandowski afirma, equivocadamente, que "nas discussões travadas na Assembleia Constituinte a questão do gênero da união estável foi amplamente debatida, quando se votou o dispositivo em tela, concluindo-se, de modo insofismável, que a união estável abrange única e exclusivamente, pessoas de sexo distinto" (ADIn n. 4.277, p. 101-102). Para fazer essa afirmação, o Ministro se baseia exclusivamente em uma manifestação do Constituinte Gastone Righi, que critica uma possível interpretação do art. $226, \S 3^{\circ}$, que estendesse a união estável às pessoas do mesmo sexo, manifestando-se favorável a uma emenda que acrescentou os artigos " $o$ homem e $a$ mulher". Além de se tratar de uma manifestação solitária, que recebe um contraponto irônico do Constituinte Gerson Peres ("A Inglaterra já casa homem com homem há muito tempo") ela foi apresentada na Comissão de Redação da Constituinte, após o texto constitucional ter sido aprovado pelo Plenário em $2^{\circ}$ turno (Diário da Assembleia Nacional Constituinte (Suplemento “B”), p. 209). 
2008). Nesses casos, o legislador aceita votar a favor de uma proposta, mesmo que ela lhe desagrade, para obter a aprovação por outro grupo de uma medida que ele considera tão ou mais importante que aquela. Fora dessas circunstâncias e sem saber de que maneira a possível emenda sobre união homoafetiva seria veiculada, não é possível responder à questão contrafactual.

O conjunto de problemas que surgem na busca da intenção do legislador (quais indivíduos devem ser levados em conta e como combinar suas intenções; quais estados psicológicos devem ser considerados para aferir a intenção do constituinte; como lidar com a situação em que o constituinte não pensou no caso) recomendam abandonar a noção de que a lei representa a comunicação de uma ideia do legislador e utilizar como ponto de partida a hipótese, muito mais provável, de que os constituintes possuem diferentes opiniões e pontos de vista sobre as matérias votadas. Dessa maneira, passa-se a seguir outro caminho de investigação, sugerido pela teoria da integridade: em vez de buscar a intenção do legislador, o intérprete deve solucionar suas dúvidas sobre a Constituição por meio de uma interpretação que torne coerente as várias decisões tomadas pelos constituintes (DWORKIN, 1999, p. 399-403). Assim, busca-se eliminar as contradições que surgem da leitura isolada dos dispositivos constitucionais subordinando-os ao conjunto da Constituição, a fim de alcançar uma solução para o caso que represente a interpretação que guarde maior coerência com esse conjunto.

Para seguir esse caminho, em vez de buscar estados psicológicos, é preciso reconhecer que o texto constitucional é o registro mais importante das decisões tomadas pelos constituintes (DWORKIN, 1999, p. 405-407; DWORKIN, 2006, p. 119-131). Sua leitura cuidadosa é a chave para formular os princípios morais e políticos que permitem reconstruir o conjunto das decisões constitucionais como um sistema coerente. São esses princípios, que devem fluir da Constituição, que fornecem as justificativas das decisões tomadas pelos constituintes e os argumentos para interpretar o texto constitucional. Portanto, a solução do problema de saber se a Constituição proíbe a extensão da união estável às relações entre pessoas do mesmo sexo deve ser buscada na interpretação dos princípios que justificam as decisões tomadas pelos constituintes sobre o tema. 
Essa interpretação deve começar pelos princípios pertinentes ao direito de família, uma vez que a Constituição contém várias normas acerca da matéria, que alteraram de maneira significativa sua regulação. Com efeito, a criação da união estável não foi a única inovação da Constituição de 1988 no direito de família. Ao contrário do que era previsto no artigo 175 da Constituição de 1969, que dispunha que a família era "constituída pelo casamento", o conjunto normativo apresentado no artigo 226 da CR reconhece que a família é destinatária da especial proteção do Estado, independentemente de sua forma de constituição. Assim, a Constituição elenca, além da família constituída pelo casamento, dois outros tipos: a união estável e a comunidade formada por qualquer dos pais e seus descendentes (art. 226, $\S 4^{\circ}$ ).

A partir dessas normas constitucionais, tanto a doutrina quanto a jurisprudência passaram a debater quais as novas características do instituto jurídico da família ${ }^{9}$, o que se mostrou necessário para adequar a legislação civil às novas diretrizes ${ }^{10}$. Desse modo, a família deixou de ser caracterizada pela sua forma de constituição, para se fundamentarem princípios como a afetividade, a estabilidade e a publicidade (LÔBO, 2002; PEREIRA, 2007), valorizando a pessoa humana mais do que suas relações patrimoniais (LÔBO, 2011, p. 22-26). A proteção constitucional conferida à família passou a ser entendida sob um ponto de vista funcional, tendo como objeto as pessoas que a integram, cujos direitos devem ser promovidos no âmbito da família' ${ }^{11}$.

9 Um fato importante nesse processo foi a criação, em 1997, do Instituto Brasileiro de Direito de Família (IBDFAM), cujos congressos e publicações se tornaram o centro das discussões sobre o tema no Brasil.

10 Lobo (2002) destaca dois casos comuns que levaram à revisão da jurisprudência sobre a matéria: a inaplicabilidade às uniões estáveis e outras entidades familiares da Súmula 380 do STF, que enquadrava o concubinato como "sociedade de fato", e a ampliação da impenhorabilidade do bem de família (Lei n $\left.{ }^{\circ} 8.009 / 90\right)$ para outras entidades familiares, tal como aquela formada por irmãos solteiros. Conferir, também, em Moreira (2012, p. 36-38).

11 “A Constituição de 1988 [...] altera o objeto da tutela jurídica no âmbito do direito de família. A regulamentação legal da família voltava-se, anteriormente, para a máxima proteção da paz doméstica, considerando-se a família fundada no casamento como um bem em si mesmo[...]. Hoje, ao revés, não se pode ter dúvida quanto à funcionalização 
Tais reflexões também levaram a comunidade jurídica a questionar se os tipos de família expressamente previstos no texto constitucional eram os únicos a serem reconhecidos juridicamente ou se a Constituição conteria uma "cláusula de inclusão" que permitiria enquadrar outras entidades familiares formadas com as mesmas características daquelas explicitadas (de modo exemplificativo) nos parágrafos do artigo 226 (LÔBO, 2002). Assim, a Constituição também tornaria possível proteger qualquer comunidade que pudesse ser definida como família, com base nos princípios já expostos ${ }^{12}$.

A recepção dessas teses pela jurisprudência, modificando os entendimentos sobre a família forjados no direito anterior à Constituição de 1988, nos permite concluir que o "pluralismo das entidades familiares" estabeleceu-se como um princípio-chave para a interpretação das normas constitucionais pertinentes ao reconhecimento e à proteção da família, baseada em suas funções constitucionais e não em sua forma de constituição. Tendo em vista seu caráter inclusivo, tal como reconheceu o próprio

da família para o desenvolvimento da personalidade de seus membros, devendo a comunidade familiar ser preservada (apenas) como instrumento de tutela da dignidade da pessoa humana" (TEPEDINO, 1999, p. 355). Outros dispositivos constitucionais, como aqueles referentes ao divórcio (art. 226, $\S 6^{\circ}$ ), à igualdade entre os cônjuges (art. 226, $\S$ $5^{\circ}$ ) e a igualdade entre os filhos (art. 227) também contribuíram para a interpretação da família como instrumento para a realização pessoal de seus integrantes.

12 Em famoso trabalho sobre o tema, Lôbo (2002, p. 90-91) identifica, com base na PNAD, as seguintes formas de família presentes na sociedade brasileira: "união de parentes e pessoas que convivem em interdependência afetiva, sem pai ou mãe que a chefie, como no caso do grupo de irmãos, após falecimento ou abandono dos pais; pessoas sem laços de parentesco que passam a conviver em caráter permanente, com laços de afetividade e de ajuda mútua, sem finalidade sexual ou econômica; uniões homossexuais, de caráter afetivo e sexual; uniões concubinárias, quando houver impedimento para casar de um ou ambos os companheiros, com ou sem filhos; comunidade afetiva formada com 'filhos de criação', segundo generosa e solidária tradição brasileira, sem laços de filiação natural ou adotiva regular". 
$\mathrm{STF}^{13}$, torna-se difícil utilizar esse princípio como fundamento da proibição do reconhecimento da união homoafetiva ${ }^{14}$.

Mas não apenas as disposições constitucionais sobre a família são relevantes para o caso. Tendo em vista a existência de uniões homossexuais em nossa sociedade, a negação de seu reconhecimento como família significa impedir que essas pessoas tenham os mesmos direitos que decorrem das uniões heterossexuais, o que caracteriza uma situação de discriminação. A questão, portanto, também envolve saber se a Constituição autoriza essa forma de discriminação, uma vez que ela estabelece como fundamentais o direito à igualdade (art. $3^{\circ}$, III e art. $5^{\circ}$, caput) e o princípio da proibição de quaisquer formas de discriminação baseada em preconceito (art. $3^{\circ}$, IV).

Tal como se verá, a decisão do STF abordou essa questão como um de seus pontos principais, o que nos levará a analisá-la de maneira mais detida na próxima seção. Porém, há um argumento contrário à invocação do direito à igualdade que deve ser logo enfrentado. Uma vez que o artigo $226, \S 3^{\circ}$, refere-se apenas à união estável entre homem e mulher, essa disposição particular deve prevalecer diante da disposição geral do direito à igualdade?

Para responder à pergunta, deve-se observar, em primeiro lugar, que ela não pode nos trazer de volta à concepção da intenção do legislador

13 "O caput do art. 226 confere à família, base da sociedade, especial proteção do Estado. Ênfase constitucional à instituição da família. Família em seu coloquial ou proverbial significado de núcleo doméstico, pouco importando se formal ou informalmente constituída, ou se integrada por casais heteroafetivos ou por pares homoafetivos. A Constituição de 1988, ao utilizar-se da expressão "família", não limita sua formação a casais heteroafetivos, nem a formalidade cartorária, celebração civil ou liturgia religiosa. [...] Dispositivo que, ao utilizar da terminologia "entidade familiar", não pretendeu diferenciá-la da família. Inexistência de hierarquia ou diferença de qualidade jurídica entre as duas formas de constituição de um novo e autonomizado núcleo doméstico". (ADIn n. 4.277, p. 3-4)

${ }^{14}$ De modo similar, ao tratar do direito à previdência social, a Constituição também estabeleceu uma cláusula inclusiva, que reconhece o direito dos companheiros, e não apenas dos cônjuges, à pensão por morte do segurado (art. 201, V). Tal como se verá posteriormente, essa disposição contribuiu para o reconhecimento dos direitos previdenciários do companheiro ou companheira homossexual. 
como um estado psicológico (DWORKIN, 1999, p. 395-399; DWORKIN, 2005, p. 64-70). Não se trata, aqui, de considerar que, embora o legislador tenha pretendido, no plano abstrato, reconhecer o direito à igualdade, sua intenção, no plano concreto das relações de família, foi a de não reconhecer as relações homossexuais. Esse ponto de vista poderia estar correto se os constituintes tivessem deixado de votar nas cláusulas gerais da igualdade caso previssem que esse direito iria possibilitar, posteriormente, o reconhecimento das uniões homoafetivas. Além dos problemas do caráter contrafactual dessa afirmação, já expostos anteriormente, essa hipótese é tão plausível quanto a oposta: os constituintes, embora se opondo às uniões homossexuais, não deixariam de votar a favor do direito à igualdade, mesmo correndo o risco de queessas uniões viessem a ser reconhecidas ${ }^{15}$.

Assim, para sustentar a interpretação de que a Constituição veda o reconhecimento da união homoafetiva, seria necessário encontrar algum princípio constitucional que, na ausência de norma proibitiva expressa ${ }^{16}$, justificasse essa forma de discriminação, ou seja, que a negação desse direito aos homossexuais representasse a interpretação mais coerente do texto constitucional. Tal princípio inexiste na Constituição de 1988, uma vez que as disposições sobre o direito à igualdade foram nela inscritas de maneira ampla, ou seja, além das situações particulares de discriminação

15 Dworkin (2005, p. 70-71) observa ainda que, mesmo que o legislador soubesse que uma concepção de igualdade diferente da sua poderia ser utilizada por outras autoridades, como os juízes, na solução de casos concretos, ainda assim ele poderia votar a favor da cláusula geral do direito à igualdade, por admitir que o direito seja transformado de acordo com a evolução da sociedade.

16 Embora sejam raras, há normas na Constituição de 1988 que não reconhecem a titularidade de direitos fundamentais para determinados grupos de pessoas. Por exemplo, o art. $12, \S 3^{\circ}$, estabelece os cargos privativos de brasileiro nato, excluindo do exercício desses direitos políticos não apenas os estrangeiros, mas também os brasileiros naturalizados. Em sua redação original, o parágrafo único do art. $7^{\circ}$ limitava os direitos dos empregados domésticos em relação aos demais trabalhadores. Cabe observar um diferença entre os dois exemplos. O rol de cargos privativos de brasileiro nato limita-se àqueles que podem exercer a chefia de Estado ou a funções estratégicas para a defesa nacional, baseando-se, portanto, no princípio da soberania (art. $\left.1^{\circ}, \mathrm{I}\right)$. Já a discriminação dos empregados domésticos não encontra apoio nos princípios constitucionais, o que ajuda a entender sua revogação. 
baseadas em preconceito que o texto constitucional expressamente rejeita, outras formas de discriminação também estão vedadas, cabendo ao intérprete identificá-las para fazer valer a Constituição. Essa interpretação também é mais coerente com a maneira aberta pela qual a Constituição consagra os direitos fundamentais, reconhecendo que aqueles que estão expressos no texto constitucional "não excluem outros, decorrentes do regime e dos princípios por ela adotados" (art. $\left.5^{\circ}, \S 2^{\circ}\right)$.

Para fundamentar ainda mais essa conclusão, é preciso aprofundar de que modo o direito à igualdade vem sendo construído, no direito brasileiro, no campo da orientação sexual. Essa discussão, no entanto, está estreitamente relacionada com a segunda questão que se pretende enfrentar nesse trabalho: o poder judiciário é competente para reconhecer a união estável homoafetiva como família? É o que se passará a examinar na próxima seção.

\section{Igualdade}

Ao julgar a Ação Penal n. 307, o STF decidiu que "escritórios profissionais" também estão protegidos pela inviolabilidade prevista no artigo $5^{\circ}, \mathrm{XI}$, da $\mathrm{CR}^{17}$, sendo indispensável o consentimento do proprietário para que qualquer pessoa possa ingressar no recinto, salvo as exceções previstas no mesmo dispositivo ${ }^{18}$.Essa decisão representou uma ampliação da hipótese prevista expressamente na Constituição, que se refere somente à "casa" como objeto da proteção constitucional.

De modo similar, o STF decidiu que "lotes vagos e prédios comerciais dados em locação" (RE n. 325.822), bem como "cemitérios" (RE n. 578.562), possuem imunidade tributária quando sejam de propriedade de instituições religiosas, embora o dispositivo constitucional invocado

\footnotetext{
17 “A casa é asilo inviolável do indivíduo, ninguém nela podendo penetrar sem consentimento do morador, salvo em caso de flagrante delito ou desastre ou para prestar socorro, ou, durante o dia, por determinação judicial".

18 A decisão citada exemplifica jurisprudência consolidada do STF, que também aplicou a garantia do art. 5, XI, por exemplo, a "quarto de hotel" (RHC 90.376) e "consultório de cirurgião-dentista". (RE 251.445)
} 
como fundamento dessa jurisprudência se refira somente a "templos de qualquer culto" (art. 150, VI, b).

Essas decisões demonstram que não estranha à jurisprudência brasileira fazer interpretações ampliativas dos direitos e garantias fundamentais. $\mathrm{O}$ aspecto comum desse tipo de decisão encontra-se no reconhecimento de que o sentido convencionalmente atribuído às palavras utilizadas no texto constitucional não elimina a possibilidade de atribuir novos sentidos às suas disposições ${ }^{19}$.

A proximidade dessas decisões com o julgado da ADIn n. 4.277 é evidente. Também nesse caso, os termos expressos na Constituição não foram considerados óbices para estender a união estável além das relações entre homem e mulher. Assim como o constituinte tinha conhecimento da existência de uniões homossexuais em nossa sociedade, ele também sabia que há outros espaços físicos em que as pessoas praticam atos da vida privada e onde as igrejas desenvolvem suas atividades, e seu silêncio sobre essas situações não foi interpretado como uma vedação ao reconhecimento de novos direitos fundamentais.

Porém, reconhecer que esse tipo de interpretação ampliativa vem sendo utilizado pela jurisprudência brasileira sobre direitos fundamentais não significa que, no caso da união estável, o STF tenha exercido corretamente suas funções. Tal como já se admitiu, a conclusão de que a Constituição não proíbe o reconhecimento da união homoafetiva não implica, necessariamente, que o poder judiciário tenha competência para realizar esse reconhecimento. As semelhanças entre as uniões heterossexuais e homossexuais não elidem a existência de diferenças, o que repõe a questão no campo da igualdade: trata-se de decidir qual é a interpretação

\footnotetext{
19 Esse tipo de decisão se baseia, muitas vezes, em analogias. Considera-se, por exemplo, que os elementos comuns entre "casa" e "escritório", ou entre "templo" e "prédios comerciais dados em locação" autorizam a extensão das normas constitucionais a casos que não estão previstos expressamente na Constituição. Tal raciocínio analógico, no entanto, deve estar baseado em algum princípio que justifique porque as semelhanças entre os casos devem ser consideradas mais relevantes do que suas diferenças. Nesses exemplos, os princípios que fundamentam a decisão são, respectivamente, o direito à privacidade e o direito à liberdade religiosa. Sobre a necessidade de utilizar princípios no raciocínio analógico, conferir em Sunstein (1996).
} 
correta do direito à igualdade nesse caso, tendo em vista que seu caráter fundamental o coloca acima do legislador ordinário. Caso a ausência de reconhecimento das uniões homoafetivas contrarie o direito à igualdade, o poder judiciário deve reparar a situação; caso contrário, o legislador terá liberdade para regulamentar ou não essas formas de união.

Como é sabido, o STF fez um amplo uso do direito à igualdade na sua decisão, o que se pode exemplificar com o voto do Ministro Ayres Britto (Relator) ${ }^{20}$.

O Ministro inicia seu voto abordando as uniões homoafetivas como aquelas que se caracterizam por sua durabilidade, conhecimento do público, continuidade e propósito de constituição de uma família, recordando ainda que, de acordo com a Constituição de 1988, o critério do sexo não pode ser utilizado como "fator de desigualação jurídica", salvo "expressa disposição constitucional em contrário". Isso implica reconhecer que está vedado o "tratamento discriminatório ou preconceituoso em razão do sexo dos seres humanos" e que o "bem de todos", previsto pela Constituição, também se alcança por meio da "eliminação do preconceito de sexo".

No que se refere às relações de família, o Ministro propõe uma interpretação "não reducionista" do instituto, que seria a mais condizente com a Constituição. Para fins da proteção do Estado, a Constituição não faria diferença entre a família constituída formalmente "e aquela existente ao rés dos fatos". Por essa razão, o casamento torna-se somente uma das modalidades de constituição da família, modificando o regime anterior. A prova disso é a própria consagração constitucional do instituto da união estável, cuja referência, no texto do artigo 226, § $3^{\circ}$, ao "homem" e à "mulher", explica-se pela tradição do mundo ocidental e pela preocupação em ultrapassar o preconceito contra a "companheira". Reconhecida a união estável como "entidade familiar" tão protegida quanto a família constituída pelo casamento, o Ministro conclui: "tanto numa quanto noutra modalidade de legítima constituição da família, nenhuma referência é feita à interdição, ou à possibilidade de protagonização por pessoas do

${ }^{20}$ ADIn n. 4.277, p. 15-46. 
mesmo sexo. Desde que preenchidas, também por evidente, as condições legalmente impostas aos casais heteroafetivos" ${ }^{21}$.

Nessas considerações, verifica-se que a orientação sexual não pode ser utilizada como critério de discriminação no âmbito das relações de família. No entanto, sabe-se que há discriminações que podem ser admitidas pela Constituição, a fim de viabilizar algum objetivo constitucional ${ }^{22}$. Estaria correta a interpretação do direito à igualdade feita pelo STF?

Uma das maneiras de responder a essa pergunta busca identificar de que modo o direito à igualdade no campo da orientação sexual vem sendo construído no direito brasileiro ${ }^{23}$. Nessa abordagem, o conteúdo normativo da igualdade encontra-se na prática constitucional desenvolvida a partir de 1988, o que inclui o conjunto de decisões legislativas, judiciais e administrativas que, consolidando-se no decorrer do tempo, demonstram qual interpretação desse direito é mais coerente em nosso ordenamento. Assim, a investigação tem como foco o conjunto de casos que, nas diferentes esferas de exercício do poder público, nos permitem dar conteúdo aos princípios constitucionais que as justificam.

21 Sobre esse ponto, vale destacar a divergência na fundamentação adotada pela maioria e os votos dos Ministros Ricardo Lewandowski, Gilmar Mendes e Cesar Peluso, para quem o reconhecimento da união homossexual pelo STF não deveria abarcar os mesmos efeitos da união heterossexual. Nas palavras do Min. Gilmar Mendes, o judiciário deveria dar uma resposta à questão, tendo em vista que a segurança jurídica estava prejudicada pela falta de legislação sobre as uniões entre pessoas do mesmo sexo, além de que cabe ao poder judiciário proteger os direitos das minorias. Porém, a decisão do STF seria uma "solução provisória", que deixaria um "espaço reservado ao regramento legislativo". Tendo em vista o caráter fundamental dos direitos envolvidos, a falta ("lacuna") de um modelo normativo de proteção institucional para a união homoafetiva justifica a aplicação da norma existente "no que for cabível” (ADIn n. 4.277, p. 191-192). As diferenças entre essa posição e aquela adotada pela maioria do STF, explicitada no item 5 da ementa do acórdão, reforça o caráter central que o direito à igualdade assumiu na fundamentação da decisão da ADIn n. 4.277.

22 Em nosso direito, o principal exemplo disso são as ações afirmativas, as quais, cabe lembrar, não são discriminações baseadas em preconceito, mas, ao contrário, buscam combatê-lo. Conferir em Rios (2008) e Brito Filho (2013).

23 Outra via importante para a discussão do tema, que não será abordada neste trabalho, analisa o papel do poder judiciário na proteção dos direitos das minorias, cf. a bibliografia referida na nota 5 . 
Tal abordagem corresponde à ideia do "romance em cadeia", que Dworkin (1999, p. 275-276) utiliza para apresentar sua teoria. Para a integridade, o direito é tratado como um conjunto coerente de princípios, explícitos e implícitos, cuja história fornece a estrutura do direito de uma determinada comunidade. Assim, o juiz deve escrever os capítulos que the cabem nesse romance fazendo com que suas decisões sejam adequadas a esses princípios e possam ser justificadas com base neles. Isso requer que a decisão judicial seja compatível com os precedentes pertinentes ao caso e represente um desenvolvimento coerente dessa história e dos princípios que a fundamentam.

Do que se trata, portanto, é identificar de que maneira a "história" da discriminação por orientação sexual foi escrita a partir de 1988. Somente a partir do exame dos capítulos anteriores à decisão do STF é que se pode julgar, de acordo com a integridade, se a união homoafetiva deve ser reconhecida pelo poder judiciário com base no direito à igualdade.

Embora a Constituição de 1988 não contenha nenhuma referência à discriminação por orientação sexual ${ }^{24}$, o tema não tardou a ingressar no sistema jurídico brasileiro, pela via das Constituições Estaduais (MAUÉS; ARRUDA, 2012). A Constituição do Estado do Mato Grosso, por exemplo, em seu artigo 10, III, prevê "[...] a implantação de meios assecuratórios de que ninguém será prejudicado ou privilegiado em razão de nascimento, raça, cor, sexo, estado civil, natureza de seu trabalho, idade, religião, orientação sexual, conviç̧ões políticas ou filosóficas, deficiência física ou mental e qualquer particularidade ou condição." Disposições similares encontram-se nas Constituições dos Estados de Alagoas (art. $2^{\circ}$, I), Sergipe (art. $3^{\circ}$, II), Pará (art. $3^{\circ}$, IV) e na Lei Orgânica do Distrito Federal (art. $2^{\circ}$, parágrafo único).

${ }^{24}$ Proposta de inclusão de disposição nesse sentido no atual art. $3^{\circ}$, IV, foi derrotada no Plenário da Constituinte por 130 votos a favor e 317 contrários (Diário da Assembleia Nacional Constituinte, n. 173, p. 421-423). De acordo com o visto na seção anterior, essa votação não pode ser tomada como prova da "intenção" dos constituintes de permitirem a discriminação por orientação sexual. 
Ainda no nível estadual, foram editadas leis com o objetivo de promover a igualdade de direitos entre as diversas orientações sexuais. Tais leis podem ser divididas, de acordo com seu objeto, em três categorias:

a) combate à discriminação: estabelecem sanções às práticas discriminatórias baseadas na orientação sexual das pessoas ${ }^{25}$;

b) educação sexual: tratam da inclusão de conteúdos sobre orientação sexual nos currículos escolares ${ }^{26}$;

c) ações afirmativas: estabelecem políticas voltadas para a promoção dos direitos dos homossexuais ${ }^{27}$.

De volta ao plano federal, somente em 2001 ter-se-á a primeira legislação que faz referência à orientação sexual, a Lei Nacional de Transtornos Mentais (Lei n. 10.216/01) ${ }^{28}$. Com maior repercussão, a Lei de Combate à Violência contra a Mulher (Lei "Maria da Penha", n. 11.340/06) também proíbe expressamente a discriminação por orientação sexual, em dois de seus dispositivos ${ }^{29}$.

25 Lei n. 2.615/00 - Distrito Federal; Lei n. 3.157/05 - Mato Grosso do Sul; Lei n. 14. 170/02 - Minas Gerais; Lei n. 7.309/03 - Paraíba; Lei n. 5.431/04 - Piauí; Lei n. 3.406/00 - Rio de Janeiro; Lei n. 12.574/03 - Santa Catarina; Lei n. 10.948/01 - São Paulo.

${ }^{26}$ Lei n. 3.576/05 - Distrito Federal; Lei n. 1.592/95 - Mato Grosso do Sul; Lei n. 12.491/97 - Minas Gerais; Lei n. 12.284/06 - São Paulo.

27 Lei n. 7.901/05 - Paraíba; Lei n. 8.225/02 - Rio Grande do Norte; Lei n. 11.872/02 Rio Grande do Sul.

28 "Art. $1^{\circ}$ Os direitos e a proteção das pessoas acometidas de transtorno mental, de que trata esta Lei, são assegurados sem qualquer forma de discriminação quanto à raça, cor, sexo, orientação sexual, religião, opção política, nacionalidade, idade, família, recursos econômicos, e ao grau de gravidade ou tempo de evolução de seu transtorno, ou qualquer outra".

29 "Art. $2^{\circ}$. Toda mulher, independentemente de classe, raça, etnia, orientação sexual, renda, cultura, nível educacional, idade e religião, goza dos direitos fundamentais inerentes à pessoa humana, sendo-lhe asseguradas as oportunidades e facilidades para viver sem violência, preservar sua saúde física e mental e seu aperfeiçoamento moral, intelectual e social" e art. 5\%: "Para os efeitos desta Lei, configura violência doméstica e familiar contra a mulher qualquer ação ou omissão baseada no gênero que lhe cause morte, lesão, sofrimento físico, sexual ou psicológico e dano moral ou patrimonial: [...] Parágrafo único: As relações pessoais enunciadas neste artigo independem de orientação sexual". 
Nota-se, portanto, que o legislador, a partir de 1988, passou a explicitar que a orientação sexual não pode ser utilizada como critério de discriminação, reconhecendo, além disso, que os preconceitos e o tratamento discriminatório existentes na sociedade devem ser objeto de políticas públicas de promoção da igualdade ${ }^{30}$.

Além dessas decisões tomadas no plano legislativo, vale destacar, também, a evolução ocorrida na esfera administrativa ${ }^{31}$. Assim, a igualdade de direitos entre uniões estáveis homoafetivas e heteroafetivas foi reconhecida em diversos campos:

a) Direitos previdenciários: adotada a partir de uma Ação Civil Pública proposta pelo Ministério Público Federal, a Instrução Normativa n. 25/00, do INSS, disciplinou o pagamento de pensão por morte e auxílio-reclusão a companheiro ou companheira homossexual. O conteúdo dessa Portaria foi ratificado pela Portaria n. 513/2010, do Ministério da Previdência Social, que estabeleceu que os dispositivos que tratam de dependentes no âmbito do Regime Geral da Previdência Social "devem ser interpretados de forma a abranger a união estável entre pessoas do mesmo sexo" $\left(\operatorname{art.} 1^{\circ}\right)^{32}$.

b) Direito à educação: a Portaria Normativa n. 5/2009, do Ministério da Educação, que regulamenta o processo seletivo do Programa Universidade para Todos (PROUNI), de concessão de bolsas em instituições particulares de ensino superior, estendeu o conceito de grupo familiar, para apuração da renda familiar (art. $6^{\circ}$,

\footnotetext{
30 O principal exemplo dessas políticas encontra-se no plano federal, com a criação do Programa Brasil sem Homofobia, a realização das Conferências LGBT e a criação do Conselho Nacional de Combate à Discriminação e Promoção dos Direitos de LGBT.

31 Para uma análise mais detalhada das inovações no plano administrativo, cf. Camargo (2011).

32 Cabe observar que o próprio STF, por meio do Ato Deliberativo 27/2009, reconheceu como dependente econômico de seus servidores "o companheiro ou a companheira de união homoafetiva estável" (art. $1^{\circ}$ ), decisão esta tomada antes do julgamento da ADIn n. 4.277. No Estado do Rio de Janeiro, a inclusão de companheiros do mesmo sexo como dependentes dos servidores públicos foi admitida pela Lei n. 5.034/2007.
} 
$\S 5^{\circ}$ ), "aos grupos familiares nos quais ocorra união estável, inclusive homoafetiva". Tal norma foi mantida nos anos seguintes.

c) Direito à saúde: a Agência Nacional de Saúde Suplementar, invocando "os princípios dispostos no texto da Constituição da República Federativa do Brasil de 1988, especialmente o da igualdade (art. $5^{\circ}$, caput), o da proibição de discriminações odiosas (art. $3^{\circ}$, inciso IV), o da dignidade da pessoa humana (art. $1^{\circ}$, inciso III), o da liberdade (art. $5^{\circ}$, caput) e o da proteção da segurança jurídica", editou a Súmula Normativa n. 12/2010, estabelecendo que "Para fins de aplicação à legislação de saúde suplementar, entende-se por companheiro de beneficiário titular de plano privado de assistência à saúde pessoa do sexo oposto ou do mesmo sexo" (art. $\left.1^{\circ}\right)$.

d) direitos dos contribuintes: respondendo a pedido de uma servidora pública federal, a Procuradoria Geral da Fazenda Nacional (PGFN), por meio do Parecer n. 1.503/2010, reconheceu a possibilidade de inclusão do companheiro ou companheira homossexual como dependente para efeito de apuração do Imposto de Renda.

Esse conjunto de decisões demonstra que, também na esfera administrativa, incorporou-se a ideia de que a orientação sexual não pode ser utilizada como critério de discriminação para negar direitos aos homossexuais, o que representou uma aplicação direta do direito à igualdade pela administração.

Por fim, no âmbito judicial, além de várias decisões que reconheciam a união estável homoafetiva ${ }^{33}$, vale lembrar o importante precedente

33 A primeira decisão reconhecendo a união homoafetiva como entidade familiar foi proferida pelo Tribunal de Justiça do Rio Grande do Sul, em 2001. No âmbito do Superior Tribunal de Justiça (STJ), o primeiro precedente significativo, de 1998, reconheceu o direito do "parceiro homossexual" receber metade do patrimônio adquirido pelo esforço comum do casal, aplicando ao caso a jurisprudência sobre sociedade de fato criada para o concubinato (REsp n. 148.897). Apesar de representar um avanço, essa jurisprudência não reconhecia as uniões homossexuais como família, o que foi mantido em outros julgados do STJ (REsp n. 323.370e REsp n. 502.995). Em 2008, o STJ mudou seu entendimento e passou a admitir a possibilidade jurídica do pedido da ação de reconhecimento de união 
firmado pelo Tribunal Superior Eleitoral (TSE), em aplicação do art. 14, $\S 7^{\circ}$, da Constituição da República, segundo qual o cônjuge de titular de cargo executivo é inelegível no território de sua jurisdição. Em 2004, ao julgar o Resp. n. 24.564/PA, o TSE decidiu que, verificada a convivência contínua e duradoura, essa norma também se aplicava à relação estável homossexual, tendo em vista sua similitude com as relações estáveis entre pessoas de sexo diferente, bem como as de concubinato e casamento.

$\mathrm{Na}$ fundamentação de seu voto, o Min. Gilmar Mendes, Relator, afirmava que, embora o ordenamento jurídico brasileiro ainda não houvesse admitido a "comunhão de vida" entre pessoas do mesmo sexo como entidade familiar, esse relacionamento deveria ter reflexo na esfera eleitoral, tendo em vista a existência nele de "forte vínculo afetivo, capaz de unir pessoas em torno de interesses políticos comuns". Em defesa dessa tese, o TSE aduzia ainda decisões judiciais anteriores que haviam reconhecido os efeitos patrimoniais e previdenciários dessas relações. Assim, embora a decisão do TSE impusesse, na prática, uma restrição de direitos como decorrência da convivência homossexual, ela também afirmava o igual tratamento das uniões entre pessoas do mesmo sexo e pessoas de diferentes sexos.

É verdade que a jurisprudência encontrava-se dividida sobre a questão, sendo inevitável, portanto, que o STF definisse qual linha de precedentes deveria ser confirmada. A decisão tomada pelo tribunal está de acordo com as exigências do direito como integridade, que impõe ao Estado respeitar os princípios do ordenamento jurídico em todos os seus $\operatorname{atos}^{34}$. Tendo sido paulatinamente eliminada do sistema jurídico brasileiro

homoafetiva (REsp n. 820.475) (Dias, 2011; Oppermann, 2011). Após a decisão do STF, o STJ julgou, em 2011, o REsp n. 1.183.378, reconhecendo a possibilidade jurídica do casamento entre pessoas do mesmo sexo. Todas as decisões citadas foram tomadas pela $4^{\text {a }}$ Turma do STJ. Moreira (2012, cap. 1 e 2) apresenta uma análise completa do desenvolvimento da jurisprudência brasileira sobre as uniões entre pessoas do mesmo sexo, identificando três fases: reconhecimento das uniões homoafetivas como sociedade de fato; reconhecimento de direitos previdenciários aos casais homossexuais; classificação como união estável e reconhecimento de direitos matrimoniais.

34 Cabe observar, ainda, que um dos argumentos utilizados pela jurisprudência para não equiparar as uniões homossexuais às uniões homossexuais baseava-se na consideração de que a diversidade dos sexos seria um elemento central da instituição da família, 
a discriminação por orientação sexual, não subsistiam mais razões para manter essa discriminação no âmbito das relações de família. Assim, o STF definiu que uma parte dessa história já não servia mais aos princípios constitucionais e reafirmou a linha de precedentes que continha os capítulos mais coerentes com o desenvolvimento do direito à igualdade no Brasil ${ }^{35}$.

\section{Conclusão}

Ao iniciar esse trabalho, foram identificadas duas críticas à decisão do STF sobre união homoafetiva: a primeira afirma que essa decisão desrespeitou as intenções do legislador constituinte; a segunda afirma que o judiciário não tem competência para reconhecer esse tipo de união.

Com base na teoria do direito como integridade, busca-se refutar essas críticas. Em relação à primeira, demonstra-se que não é possível identificar que os constituintes tiveram a intenção de proibir o reconhecimento das uniões homoafetivas, uma vez que não se sabe como combinar as intenções dos vários legisladores, quais de seus estados psicológicos devem ser considerados, nem como lidar com a situação em que os constituintes não pensaram no caso. Em substituição a essa abordagem, busca-se interpretar as decisões dos constituintes a partir dos princípios que emanam da Constituição, verificando que o pluralismo das entidades

justificando uma discriminação fundada no interesse estatal da promoção da procriação (MOREIRA, 2012, p. 103). Contudo, tal como vimos, as normas constitucionais sobre a família foram interpretadas para proteger as famílias independentemente da procriação e mesmo aquelas em que isso não é possível, tal como as comunidades de irmãos.

${ }^{35}$ Após a decisão do STF, foi apresentado na Câmara dos Deputados o Projeto de Decreto Legislativo n. 325/2011, visando "sustar a aplicação da decisão do Supremo Tribunal Federal [...] que reconhece a estabilidade da união homoafetiva". Essa proposição foi devolvida pela Mesa por versar sobre matéria "evidentemente inconstitucional", nos termos do artigo 237, § $1^{\circ}$, II, b, do Regimento Interno da Câmara dos Deputados. Segundo o entendimento da Mesa, "[...] uma suposta intromissão indevidas do Poder Judiciário sobre as prerrogativas do Legislador só é sanável pelo próprio exercício do poder de legislar ou, conforme o caso, de reformar a Constituição". Como se sabe, nenhuma das duas medidas foi aprovada pelo Congresso Nacional até agora. 
familiares e o direito à igualdade permitem o reconhecimento das uniões homoafetivas como família.

Em relação à segunda crítica, demonstra-se que a maneira como o STF interpretou o direito à igualdade no caso, excluindo o uso da orientação sexual como critério de discriminação, encontra apoio na interpretação da igualdade desenvolvida na prática constitucional brasileira a partir de 1988. Assim, verifica-se que uma série de decisões legislativas, administrativas e judiciais foi paulatinamente eliminando esse critério de discriminação da ordem jurídica brasileira, cabendo ao STF confirmar que essa também é a interpretação mais coerente com os princípios constitucionais no campo do direito de família.

Dessa forma, construiu-se uma fundamentação da decisão da ADIn n. 4.277 que permite concluir que ela representou uma interpretação correta da Constituição, afastando as críticas inicialmente apontadas. Podese observar, ainda, que o caso traz um ensinamento para outras demandas por direito fundamentais. Nele, a luta pelo reconhecimento de direitos utilizou todas as vias institucionais do Estado brasileiro, obtendo conquistas que, embora pontuais, vão acrescentando novos capítulos à história, até o momento em que ela passa a ser contada de outra maneira, mais compatível com o que recomeçou a ser escrito em 1988.

\section{Referências}

BAHIA, Alexandre Gustavo Melo Franco; VECCHIATTI, Paulo Roberto Iotti. ADI n. 4.277 - Constitucionalidade e relevância da decisão sobre união homoafetiva: o STF como instituição contramajoritária no reconhecimento de uma concepção plural de família. Revista Direito GV, São Paulo, v. 9, n. 1, p. 65-92, jan-jun. 2013.

BRITO FILHO, José Claudio Monteiro de. Ações afirmativas. 2. ed. São Paulo: LTr, 2013.

CAMARGO, Sérgio Alexandre. Conquistas administrativas do direito homoafetivo. In: DIAS, Maria Berenice (Coord.). Diversidade sexual e direito homoafetivo. São Paulo: Revista dos Tribunais, 2011. 
DIAS, Maria Berenice. Rumo a um novo ramo do Direito. In: DIAS, Maria Berenice (Coord.). Diversidade sexual e direito homoafetivo. São Paulo: Revista dos Tribunais, 2011.

DWORKIN, Ronald. O império do direito. São Paulo: Martins Fontes, 1999.

\section{5.}

. Uma questão de princípio. 2. ed. São Paulo: Martins Fontes,

. Justice in robes. Cambridge: Harvard University Press, 2006.

EKINS, Richard. The nature of legislative intent. Oxford: Oxford University Press, 2012.

GOLDSWORTHY, Jeffrey. Dworkin as na originalist. Constitutional Commentary, v. 17, n. 1, p. 49-79, 2000.

LÔBO, Paulo Luiz Netto. Entidades familiares constitucionalizadas: para além do numerusclausus. In: PEREIRA, Rodrigo da Cunha (Coord.). Família e cidadania: o novo CCB e a vacatio legis. Belo Horizonte: IBDFAM/Del Rey, 2002. p. 89-107.

LÔBO, Paulo. Direito civil: famílias. 4. ed. São Paulo: Saraiva, 2011.

LOPES, Júlio Aurélio Vianna Lopes. A carta da democracia: o processo constituinte da ordem pública de 1988. Rio de Janeiro: Topbooks, 2008.

MAUÉS, Antonio Moreira; SANTOS, Élida Lauris dos. Estabilidade constitucional e acordos constitucionais: osprocessos constituintes de Brasil (1987-1988) e Espanha (1977-1978). Revista Direito GV, São Paulo, v. 4, p. 349-387, 2008.

MAUÉS, Antonio Moreira; ARRUDA, Paula. Instituições. Formações sociais diversas da família e condição dos homossexuais no Brasil. In: POMPEU, Gina Vidal Marcílio; SCAFF, Fernando Facury. (Org.). Discriminação por orientação sexual. Florianópolis: Conceito, 2012. p. 191-204.

MENEZES, Joyceane Bezerra de; OLIVEIRA, Cecilia Barroso de. ADI 4.277: uma discussão sobre a legitimidade do STF. Novos Estudos Jurídicos, Itajaí, SC, v. 17, n. 3, p. 501-515, set.-dez. 2012. 
MOREIRA, Adilson José. União homoafetiva: a construção da igualdade na jurisprudência brasileira. 2. ed. Curitiba: Juruá, 2012.

NIGRO, Rachel. A decisão do STF sobre a união homoafetiva: uma versão pragmática da linguagem constitucional. Direito, Estado e Sociedade, Rio de Janeiro, n. 41, p. 157-183, jul-dez. 2012.

OPPERMANN, Marta Cauduro. Competência das varas de família. In: DIAS, Maria Berenice (Coord.). Diversidade sexual e direito homoafetivo. São Paulo: Revista dos Tribunais, 2011.

PEREIRA, Sumaya Saady Morhy. Direitos fundamentais e relações familiares. Porto Alegre: Livraria do Advogado, 2007.

PILATTI, Adriano. A Constituinte de 1987-1988. Progressistas, conservadores, ordem econômica e regras do jogo. Rio de Janeiro: Lumen Juris, 2008.

RIOS, Roger Raupp. O princípio da igualdade e a discriminação por orientação sexual. São Paulo: Revista dos Tribunais, 2002.

RIOS, Roger Raupp. Direito da antidiscriminação: discriminação direta, indireta e ações afirmativas. Porto Alegre: Livraria do Advogado, 2008.

RIOS, Roger Raupp; GOLIN, Célio; LEIVAS, Paulo Gilberto Cogo (Org.). Homossexualidade e direitos sexuais: reflexões a partir da decisão do STF. Porto Alegre: Sulina, 2011.

STRECK, Lenio Luiz; BARRETTO, Vicente de Paulo; OLIVEIRA, Rafael Tomaz de. Ulisses e o canto das sereias: sobre ativismos judiciais e os perigos da instauração de um terceiro turno da constituinte. Revista de Estudos Constitucionais, Hermenêutica e Teoria do Direito, São Leopoldo, RS, n. 2, p. 75-83, 2009.

SUNSTEIN, Cass. Legal reasoning and political conflict. Oxford: Oxford University Press, 1996.

TEPEDINO, Gustavo. Temas de direito civil. Rio de Janeiro: Renovar, 1999. 
VENOSA, Sílvio. Direito civil: direito de família. 8. ed. São Paulo: Atlas, 2008.

Antonio Moreira Maués é Professor associado da Universidade Federal do Pará, possui mestrado em Ciências Jurídicas pela Pontifícia Universidade Católica do Rio do Janeiro e doutorado em Direito pela Universidade de São Paulo. E-mail:ammaues@uol.com.br Endereço profissional: Universidade Federal do Pará, R. Augusto Corrêa, 1. CEP: 66075-110, Belém - PA. 